\title{
"La nueva educación que los trabajadores queremos". Luz y Fuerza Capital Federal y su proyecto de formación integral (1962-1975)
}

\author{
"The new education that we workers want": Luz y Fuerza Capital Federal and its \\ project of comprehensive training (1962-1975)
}

\author{
Gabriela Scodeller \\ gabriela.scodeller@gmail.com \\ Instituto de Ciencias Humanas, Sociales y \\ Ambientales. Centro Científico Tecnológico Mendoza. \\ Facultad de Ciencias Políticas y Sociales. Universidad \\ Nacional de Cuyo / CONICET, Argentina
}

Recepción: 04 Mayo 2020

Aprobación: 31 Agosto 2020

Publicación: 01 Septiembre 2021

Cita sugerida: Scodeller, G. (2021). "La nueva educación que los trabajadores queremos”. Luz y Fuerza Capital Federal y su proyecto de formación integral (1962-1975). Sociohistórica, 48, e148. https://doi.org/10.24215/18521606e148
Resumen: El artículo se propone explorar la puesta en marcha del proyecto educativo que impulsó el Sindicato Luz y Fuerza Capital Federal en los años sesenta y setenta en Argentina. Como parte de su concepción de un "sindicalismo múltiple y de participación”, el mismo procuró la formación políticosindical de activistas y cuadros medios, pero también, una educación cultural integral que abarcase a toda la "familia lucifuercista" y a trabajadores de otros gremios. El lugar estratégico de la formación se anudaba a su meta por lograr una cada vez mayor participación de los trabajadores en los ámbitos de gestión empresarial y de poder estatal. A partir de un recorrido sustentado en fuentes documentales de la propia organización, se formulan una serie de interrogantes a los abordajes historiográficos sobre el período y se discute la necesidad de revisar ciertos supuestos e interpretaciones sobre actores y prácticas.

Palabras clave: Sindicatos, Educación obrera, Participación, Argentina, Años sesenta.

Abstract: The article aims to explore the implementation of the educational project promoted by the Luz y Fuerza Capital Federal Union in the 1960s and 1970s in Argentina. As part of its conception of a "multiple and of participation unionism", it pursued the political training for its activists and middle cadres, but also, a broad cultural education destined to the entire "lucifuercista family" and to other unions' workers. The strategic place of training was tied to its goal to achieve an increasing participation of workers in the field of business management and state power. From a description supported on documentary sources elaborated by the organization, we formulate a series of questions regarding the historiographic approaches to the period and pose the need to review certain assumptions and interpretations about actors and practices.

Keywords: Unions, Workers education, Participation, Argentina, Sixties. 


\section{INTRODUCCIÓN}

$\mathrm{El}^{1}$ presente artículo busca poner el foco sobre una fracción del sindicalismo y sobre un tipo de acción sindical poco atendidos a la hora de pensar el ciclo de protestas de la Argentina de los años sesenta y setenta. Nos referimos al llamado "participacionismo", aludido tangencialmente en la bibliografía secundaria sobre el período -más preocupada por reponer las luchas, experiencias y memorias de las corrientes combativas o clasistas-. A su vez, dada la intensidad y radicalidad de la conflictividad social a lo largo del período, los aspectos vinculados a la formación de los y las trabajadores no suelen considerarse como una práctica sindical, y, por tanto, como parte de dicha dinámica de lucha. En el marco de un estudio más amplio, que se pregunta por el vínculo entre los derroteros de la lucha de clases en los años setenta y los modos y contextos en que la clase obrera realiza un aprendizaje acerca de su propia práctica y la de otras, nuestra hipótesis es que fueron los sectores sindicales reformistas, es decir, aquellos comprometidos con el sostenimiento del orden vigente, quienes otorgaron un lugar central a la formación político-sindical, librando una disputa por sus contenidos y formas.

En este sentido, y como parte de dicho universo sindical reformista, ${ }^{2}$ recalamos en el Sindicato de Luz y Fuerza Capital Federal (SLyF), puesto que prestó una importancia superlativa a los aspectos de formación técnica, política y gremial, en relación con otras experiencias sindicales contemporáneas. ${ }^{3}$ Ello se vincula a la concepción sobre el rol que los sindicatos debían asumir en la sociedad y al tipo de dirigentes que debía prepararse en sintonía para desempeñar funciones tanto dentro como fuera del gremio, al amparo de su "filosofía de la participación". Este escrito busca ordenar las distintas acciones de formación diseñadas y/o impulsadas por dicho sindicato, prestando particular atención a las actividades desplegadas desde el Instituto de Capacitación Sindical (ICS) creado en 1962. Sin embargo, y como se podrá ver, la formación de cuadros sindicales fue, aunque muy importante, una de las tantas aristas en las que se concentró el sindicato, formulando una concepción y propuesta integral de educación obrera.

Procuramos dilucidar cuál era la mirada desde las dirigencias obreras sobre el tema, sus líneas estratégicas e intereses políticos, desarrollos teóricos y propuestas pedagógicas. Las fuentes en que se sustenta la investigación son publicaciones de diversa índole, tanto del sindicato como de la Confederación General del Trabajo (CGT), junto a materiales utilizados en las instancias de formación, disponibles en distintas bibliotecas y acervos documentales. ${ }^{4}$

Como se verá, el análisis de este actor y esta arista de la vida gremial además lleva a poner en tensión ciertos esquemas interpretativos que reducen la participación, en términos formales, al desarrollo de instancias de toma de decisiones, en las que la asociación que se teje entre la presencia de una clase obrera combativa -y a veces revolucionaria- con los niveles de movilización obrera descansa en la existencia de una sólida democracia interna, entendida como una amplia y activa participación de las trabajadoras y los trabajadores en el devenir organizacional (Ghigliani, 2009). El caso estudiado aquí sugiere cautela respecto de dichos abordajes historiográficos.

\section{SINDICALISMO MODERNO, SABER Y PODER}

Surgido en 1943, el sindicato nucleó al personal de todas las categorías (manual y no manual) de las empresas de producción, transmisión, distribución y comercialización de energía eléctrica de la Capital Federal y el Gran Buenos Aires: Agua y Energía Eléctrica, Compañía Ítalo Argentina de Electricidad (CIAE) y Servicios Eléctricos del Gran Buenos Aires (SEGBA) -la principal-. Constituía, para la etapa aquí recorrida, el mayor sindicato del sector, ${ }^{5}$ lo que lo convertía en la organización predominante dentro de la Federación Argentina de Trabajadores de Luz y Fuerza (FATLyF), situación motivada además por la 
"secuela de convenios colectivos sumamente ventajosos" (Graziano, 1989, p. 66) y el crecimiento vertiginoso de una estructura proveedora de servicios sociales a sus afiliados. ${ }^{6}$

Política e ideológicamente suele ser ubicado dentro de la tendencia "participacionista". Las referencias a la misma en la historiografía suelen presentar cierta ambigüedad, en relación a: cuándo surge y hasta cuando pervive -ya sea que se la considere como una corriente profunda del movimiento obrero o como un nucleamiento específico-, qué gremios la integraron y las características estructurales de los mismos, sus posicionamientos políticos, prácticas sindicales y concepciones ideológicas. Se la confunde contemporáneamente en las fuentes y posteriormente en los estudios de diversa índole sobre el períodocon los llamados colaboracionistas o dialoguistas, con variantes del vandorismo, los No Alineados y/o la Nueva Corriente de Opinión (NCO). La definición más refinada de dicha corriente sea quizá la de A. Fernández (1986), pero dentro de esta Luz y Fuerza Capital no encaja cómodamente, o queda desdibujado, por cuanto estamos hablando de un sindicato de peso dentro de la estructura sindical argentina por su desarrollo organizativo, patrimonial, altos niveles de afiliación y que representa a un sector estratégico de la economía (Ghigliani y Grigera, 2011; Haidar, 2017), el que a su vez se distanció de aquella al poco tiempo y tampoco formó parte de la NCO. ${ }^{7}$ Si bien Fernández ubica al SLyF dentro de la tendencia participacionista (1986, p. 63) -la cual en el período 1966-73 fue creciendo en influencia y “desarrollándose a expensas del vandorismo" (p. 64) - también señala que se trataba de un "sindicato influido por algunas ideas desarrollistas y próximo al 'participacionismo' en un momento (1968), pero sobre todo adalid de una concepción autonomizante del sindicalismo” (pp. 22-23).

A su vez, los escasos estudios que se han ocupado del SLyF en esta etapa (Grau, 2007; Dawyd 2012), si bien han ahondado en su caracterización, han mantenido dicha identificación con el término participacionismo o participacionistas, que a nuestro entender desdibuja y no permite dar cuenta de la especificidad del mencionado sindicato. Un obstáculo de estas, si lo que se busca es mirar el problema desde la perspectiva de los trabajadores, es que su existencia se asocia directamente a la convocatoria efectuada por el gobierno militar de J. C. Onganía a incorporarse dentro de su esquema corporativista. ${ }^{8}$ Esto los coloca en un lugar de subordinación, ${ }^{9}$ y diluye así una aspiración que, en el caso de Luz y Fuerza, venía no solo formulada sino concretizada en la figura de los directores obreros desde $1964 .{ }^{10}$ Se desconoce, además, un marco global de discusiones y disputas por parte de ciertos sectores sindicales reformistas interesados en la cuestión de la participación sindical en ámbitos (inter)gubernamentales de definición de políticas (Rodríguez García, 2010; Scodeller, 2015). Por ello preferimos referirnos a esta fracción del movimiento obrero como sindicalismo de participación o sindicalismo de acción múltiple. Nos resulta más ajustado y preciso por cuanto retoma la propia definición de los actores, sin caer en una calificación peyorativa a priori.

Luego de identificarse con la denominación de sindicalismo de acción múltiple, el núcleo dirigencial que condujo el sindicato en los años sesenta y setenta entendía que las organizaciones obreras no debían limitar su acción a un plano meramente sindical -el que a su vez era comprendido en un sentido amplio, que contemplaba aspectos gremiales y culturales, tanto para el trabajador como para su familia-, sino que debían ocuparse del conjunto de la vida política y económica nacional. En este sentido, proyectó un modelo de país ${ }^{11}$ en el cual se pugnaba por que la clase trabajadora fuera partícipe "no solo en los cambios, sino también en la dirección de los mismos". ${ }^{12}$ Según esta “teoría de la acción múltiple” y "participación integral” que Luz y Fuerza formuló:

no se trata solamente de atender a las necesidades de los trabajadores, o de defender sus derechos; se trata de lograr la participación activa y responsable de aquellos que mayoritariamente forman parte de un pueblo. Una participación que se refiere a los centros del poder real, a las decisiones políticas, económicas y sociales. ${ }^{13}$

Era una concepción que abrevaba fuertemente en la Doctrina Social de la Iglesia y en la ideología justicialista en cuanto a las nociones sobre armonía entre capital y trabajo, o sobre la propiedad como 
bien común con función social, ${ }^{14}$ pero que fue más allá en la formulación del lugar que correspondía a los trabajadores en las instancias de gestión, tanto de las empresas como del Estado. ${ }^{15}$

En esta línea, en el balance que el SLyF realizaba de su accionar a lo largo de los años, que reconocía logros, pero también la necesidad de seguir avanzando, el lugar que daba a la formación era central:

Hemos realizado dos etapas revolucionarias: la reivindicativa y la de la acción múltiple con el campo social; pero no podemos detener allí la dinámica revolucionaria, debemos luchar para consolidar y perfeccionar todo lo realizado, logrando, definitivamente, nuestra participación activa en todos los niveles de conducción empresaria y nacional, para ello debemos perfeccionar nuestra Organización y lograr niveles doctrinarios aptos... (SLyF CF, 1965-1966, p. 6).

Como muestra la cita anterior, el hilo que articulaba formación y sindicatos para Luz y Fuerza era su concepción en torno a la participación de los trabajadores y sus organizaciones en las esferas de gestión económica y política, por cuanto debían capacitarse a fin de contar con las herramientas adecuadas que les permitiesen discutir y exigir su lugar en las distintas esferas de toma de decisiones. Sin embargo, manteniendo este objetivo transversal, su política educativa también se fue ampliando, modificando y adecuando a los cambiantes contextos de la Argentina. Por ello vale la pena recorrer las consignas con que desde el ICS se convocaba a sus actividades.

Siempre en busca del "perfeccionamiento" ${ }^{16}$ de los militantes gremiales, es decir, que "logren dentro de su campo de acción sindical, manejarse con los mejores elementos técnicos, estadísticos, morales, éticos, etc." (SLyF CF, 1967b, p. s/n), la formación estuvo asociada a distintas ideas ordenadoras: la justicia social (con mayor énfasis hasta 1971) ${ }^{17}$, la revolución entendida en clave nacional y cristiana (de manera constante) ${ }^{18}$, la liberación y el socialismo nacional (más claramente desde 1973) ${ }^{19}$. A fin de tener una imagen completa del perfil que se buscaba dar a los cuadros sindicales a través de la formación, es necesario combinar lo anterior con la insistencia que el SLyF ponía en la construcción de un sindicalismo ajustado a los tiempos vividos. En esta línea, afirmaban que los distintos cursos y actividades del ICS constituían una "contribución... dentro del Sindicalismo moderno, para la formación doctrinaria de los militantes sindicales..." (SLyF CF, 1967b, p. s/n) ${ }^{20}$.

Luz y Fuerza no era original en este aspecto. Entroncaba con planteamientos que habían tomado fuerza en el mundo de la segunda posguerra, y que pregonaban la modernización de las funciones y responsabilidad de las organizaciones sindicales (Scodeller, 2015). En este cuadro global, la OIT fue una referencia muy atendida. De hecho, en 1967 la revista Dinamis reproduce una nota del experto en educación y sindicatos de dicha organización Georges Vidalenc, en la que se explayaba sobre la figura de un nuevo militante sindical, quien además de haberse formado en la práctica como sus antecesores,

han recibido una formación más completa respecto a la organización científica del trabajo, a la estructura y la administración de la empresa, al Código del trabajo, a la evolución general de la economía, a la ordenación territorial, al estudio de la coyuntura y a la política de planificación. ${ }^{21}$

En este marco puede comprenderse mejor el interés del SLyF por las Ciencias Sociales y la búsqueda de vínculos con técnicos o expertos de dichas áreas; eran aliados estratégicos, capaces de aproximar al mundo sindical la producción proveniente de ámbitos académico-científicos. ${ }^{22}$ Sin embargo, no se trataba solo de recuperar esos conocimientos para el movimiento obrero, sino de asumir un rol activo en la producción de datos y análisis que mejorase su quehacer militante.

Ejemplo de ello fue el Censo de Afiliados que el Centro de Estudios Económicos y Sociales (CEES) dependiente de la Secretaría General Técnica del Sindicato- realizó en 1969-1970. ${ }^{23}$ Con esta perspectiva de utilizar "la investigación técnica y científica... como instrumento al servicio de la masa de trabajadores y del pueblo", ${ }^{24}$ ya en 1967 se había firmado un convenio con el Instituto de Sociología de la Universidad de Buenos Aires (UBA) para realizar una encuesta sobre condiciones y características de vida de los trabajadores de la industria manufacturera de la Capital Federal y Gran Buenos Aires. Como decíamos, en esta relación 
los trabajadores tenían un lugar importante que ocupar; no eran meros depositarios del saber académico. Destaquemos que en el proyecto anteriormente mencionado - que buscaba conocer los efectos de la inflación y “organizar planes y/o propuestas gremiales” en materia de vivienda y educación-, la dirección recaía sobre el CEES, mientras que la UBA aportaba ayudantes de investigación y procesaba los datos. ${ }^{25}$

Se apelaba al conocimiento científico-académico, aunque siempre se lo consideraba de modo articulado con los saberes prácticos que el sindicalismo en general, y Luz y Fuerza en particular, construía histórica y cotidianamente. Un ejemplo significativo de este ensamblaje fue la elaboración del trabajo que se publicó a fines de 1972 bajo el título de "Pautas para una política nacional". Esto era entendido como "un programa nacional (...) con un alto contenido y una alta participación popular” y Alberto Delfico explicó que su elaboración había arrancado a fines de 1971 junto a un conjunto de intelectuales -cuyos nombres nunca se mencionan-:

comenzamos a hablar con un grupo de distintas disciplinas para interesarlos en la idea, y les especificamos concretamente nuestro objetivo: queremos un programa de gobierno, pero queremos que sea realizable... Esto posibilitó un fenómeno infrecuente: que un grupo de intelectuales se acercara al movimiento obrero y descubriera que entre ambos hay más puntos de contacto que lo que suele creerse ${ }^{26}$.

A su vez, enfatizaba: "el trabajo no es sólo de ellos sino que el Sindicato ha volcado allí sus propias investigaciones, ideas y puntos de vista". ${ }^{27}$

Así como Luz y Fuerza confiaba en sus propios saberes, en un sentido similar puede observarse un interés entre los cuadros sindicales por construir conocimientos a partir de experiencias contemporáneas más allá de las fronteras nacionales. Es así que, en el marco de un viaje por Europa a fines de 1971 para conocer distintas experiencias de participación sindical, los cinco dirigentes involucrados durante su gira no dejaron de mirar y tomar nota de las actividades de formación que en los distintos países visitados realizaban las organizaciones sindicales, recuperando fundamentalmente la labor de la Confederación Francesa Democrática del Trabajo. ${ }^{28}$

Las nociones aludidas en este apartado y que el SLyF buscó hacer carne entre sus afiliados circularon ampliamente a través de una permanente política de comunicación interna, implementada fundamentalmente desde la revista Dinamis en sus distintos formatos (mural, quincenal, interno, etc. $)^{29}$. Pero la difusión de su acción y pensamiento se extendió también puertas afuera del sindicato o del lugar de trabajo, desde que a mediados de 1968 se define que, en su versión mensual, esta pase a ser parte del circuito comercial de venta callejera (SLyF CF, 1966-1967, pp. 96-97) ${ }^{30}$. Para ello, como para la edición de un número importante de publicaciones, contó con su propia imprenta, 2 de Octubre.

En síntesis, la búsqueda sistemática de participación en esferas decisorias de la vida política nacional requería de un sindicalismo acorde a los tiempos, con una clase dirigente preparada y trabajadores igualmente formados técnica y políticamente. De allí la centralidad que ocuparía en su esquema o "filosofía de la participación" ${ }^{31}$ la formación. Esta tarea, como era de esperarse, tampoco fue dejada en manos ajenas. En tanto organización obrera, afirmaban: "es nuestra obligación brindar la oportunidad de capacitar al hombre para lograrlo por sí mismo. Si así lo hace, nosotros habremos cumplido con nuestra misión”32. Embebido como vimos en el catolicismo social,[33] este objetivo no se reducía a la formación del militante gremial, sino que apelaba al trabajador como ser social más allá del trabajo, a su "deseo de instrucción" y "sed de saber". ${ }^{34}$ Por esta perspectiva integral, que incluía a todo miembro del sindicato y su familia, comenzaremos nuestro recorrido. 


\section{SINDICATO Y EDUCACIÓN: UNA MIRADA INTEGRAL}

En términos estrictamente educativos, ${ }^{35}$ fue el propio sindicato el que estableció una clasificación entre cuatro tipos de formación, según sus modalidades y funciones. Estas a su vez presentan cierta correspondencia con las etapas históricas por las que ha atravesado el movimiento obrero, aunque también podrían darse simultáneamente o surgir según el estadio de desarrollo de cada gremio. Así, en primer lugar, la "formación técnica" o "capacitación para el trabajo mismo" acompañó un momento "inicial de mero ajuste laboral". Luego seguía la "formación sindical" propiamente dicha, entendida como una "capacitación para la conducción gremial", a su vez vinculada a una etapa de "lucha gremial". Un tercer tipo era la "formación social o humana”, que incluía desde actividades que propiciaban el desarrollo personal, hasta aquellas que hacían al manejo y administración de las obras sociales y demás servicios sindicales. Esta se correspondía con un momento de la historia del movimiento obrero de "conquistas sociales y humanas". Finalmente, estaba "la formación para la conducción de las empresas y del estado", correspondiente a una etapa "que recién comienza”, en la que los sindicatos "apuntan a participar políticamente a través de la autogestión empresaria y en la gestión de gobierno" (SLyF CF, 1974b, p. 5). En el caso del SLyF, los cuatro tipos de formación reseñados se llevaban a la práctica simultáneamente. Veamos algunos ejemplos.

En el primer tipo entran los cursos que el sindicato dictaba en las empresas de energía atendiendo a la demanda de capacitación profesional (inglés, electricidad, albañilería, canalización, comunicaciones, máquinas IBM, alta tensión, subestaciones, instrumentista, proyectista, telefonista, contabilidad, entre otros ${ }^{36}$. Estos estaban a cargo de la Comisión de Capacitación y Becas, dependiente de la Secretaría Gremial, quienes también se ocupaban de las becas de estudio secundario y universitario por CCT para trabajadores y familiares. En línea con esta atención al perfeccionamiento profesional, en 1975 se firmó un convenio con el Consejo Nacional de Educación Técnica (CONET) que apuntaba a la "formación de técnicos de nivel medio en la especialidad Electromecánica”, lo cual se implementó -en una etapa experimental- mediante un Ciclo Superior de modalidad intensiva. ${ }^{37}$

Dentro del segundo tipo están los programas del Instituto de Capacitación Sindical, a los que nos referiremos en detalle a continuación. Con un importante sustrato político, su accionar se proyectaba para el activismo sindical en sus distintos niveles, aunque con el tiempo se fue ampliando el marco de destinatarios.

Como ejemplo del tercer tipo, el SLyF coloca las actividades, cursos y carreras organizadas a través de su Escuela de Artes y Especialidades o del Instituto Femenino Sindical, tales como, artes plásticas, dibujo, pintura, fotografía, teatro, expresión corporal, foniatría, historia del arte, música, canto, danzas, guitarra, vocalización, piano, coro, orquesta de cámara, ballet, relaciones humanas, cosmetología, periodismo, manicura, decoración, costura y bordado, peinado, arte culinario, pedicuría, gimnasia modeladora, dibujo publicitario, yoga, ikebana, manualidades, secretariado comercial, inglés, dactilografía, taquigrafía, castellano, matemática, contabilidad, o francés. Desde 1973 los cursos profesionales fueron reconocidos oficialmente por el CONET, y se les otorgaron certificados habilitantes de validez nacional -ya que la propia institución prestaba a esta Escuela asesoramiento pedagógico y técnico- ${ }^{38}$ También ubican, como parte de este tipo de "formación social y humana", la educación física y el entrenamiento deportivo, los cuales se canalizaban a través del Departamento Juventud.

Asimismo, bajo el eslogan "Cultura del pueblo y para el pueblo", entraba la tarea de la Escuela Media Comercial, que funcionó desde 1972. Esta permitía a afiliados y familiares -luego se aceptó a cualquier mayor de edad y trabajador/a- obtener de modo acelerado el título de perito mercantil con validez nacional, para adecuarse, de este modo, "a las reales características y necesidades del adulto actual" (SLyF CF, 1972a, p. 3) 39 . En la misma línea, en acuerdo con la Dirección Nacional de Educación del Adulto (DINEA), posteriormente se inauguraron cinco Centros de Estudio de Nivel Secundario (CENS) bajo la modalidad de bachilleratos. ${ }^{40}$ 
Además, Luz y Fuerza colaboró con la propuesta de DINEA de "creación de Centros de Cultura Popular" prestando espacios físicos a dicho fin. ${ }^{41}$

Este tipo de "formación social y humana", sobre todo a lo largo de 1974, se amplió significativamente, a través de la firma de una serie de convenios con instituciones educativas de distinta índole. ${ }^{42}$ Según el propio ICS, el objetivo de "establecer contactos con institutos similares, Centros de Estudios socio-políticos y Universidades” perseguía el fin de "ir compenetrándonos mutuamente de las necesidades de la Comunidad en aras a preparar, con visión y patriotismo, en grandeza y dignidad, la Argentina que queremos para nuestros hijos" (SLyF CF, 1973, p. 25).

Cuando a fines de diciembre de 1973, ante una gran asamblea de delegados, se firmaron algunos de los convenios mencionados, la presencia de las autoridades gubernamentales en dicho acto se interpretó como una validación de las actividades educativas que el sindicato venía desarrollando. ${ }^{43}$ Sintetizando la visión que sostenía su mirada educativa y en la que articulaban participación y una promoción cultural en sentido amplio -en clave "nacional" y "popular"-, se planteó:

Permanentemente decimos "Cultura del Pueblo y para el Pueblo", y ¿quién mejor indicado para cumplir este lema que una organización gremial?

Hacemos cultura sí, pero auténticamente popular; hacemos educación sí, pero auténticamente popular. A través de la cultura y la educación que interpretamos y pregonamos creamos conciencia para entender y para sentir el país, NUESTRO PAIS. $^{44}$

Finalmente, como ejemplos del cuarto tipo de formación -aquella "para la conducción empresarial y gubernamental”-, señalan los cursos sobre autogestión que en 1973 se realizaron en la empresa SEGBA y los seminarios intensivos sobre Participación-Cogestión-Autogestión, que se dictaron en el marco de los Cursos Básicos del ICS durante 1973 y 1974 -sobre los que volveremos más adelante-.

$\mathrm{Al}$ respecto de las distintas acciones mencionadas, el entonces secretario de Cultura del SLyF, Hugo Caruso, sostenía que no se trataba de competir con otras instituciones sino "de que el trabajador, como protagonista del proceso de liberación, no renuncie al papel que le corresponde participando en su propio proceso educativo" (SLyF CF, 1974a, p. 5). Acorde al pensamiento lucifuercista, no se trataba solo de tener un trabajador más preparado -técnica, política y culturalmente-, sino de ser parte del proceso de definición de los conocimientos que este requería.

\section{La Formación de cuAdros Sindicales: el Instituto de Capacitación Sindical}

Como enunciamos al inicio de este artículo, nos interesa particularmente lo que en el propio esquema de Luz y Fuerza sería el segundo tipo de formación, y que fue instrumentado fundamentalmente desde el ICS.

Este comenzó a funcionar en 1962. Dependía de uno de los departamentos de la Secretaría de Cultura, el de Capacitación Sindical. ${ }^{45}$ A partir de entonces, y hasta su interrupción por la intervención que sufre el sindicato con el golpe de $1976,{ }^{46}$ realizó una intensa y variada actividad. Retomando algunos de los puntos que hemos enunciado en el primer apartado, así sintetizaban su rol y concepción:

\footnotetext{
Vista la necesidad que el sindicalismo moderno experimenta en las actuales circunstancias, caracterizadas por la irrupción de la ciencia y la tecnología, como factores esenciales del progreso de las naciones, de contar con dirigentes que se interesen por la interpretación de los fenómenos económico-sociales de nuestra época y el deseo de orientar la participación de los trabajadores en el análisis y solución de los problemas nacionales, promoviendo la actividad gremial de mujeres y hombres de nuestra Organización, el Instituto de Capacitación Sindical de Luz y Fuerza ha concentrado sus esfuerzos en el estudio, investigación y adiestramiento de sus cuadros sindicales, para proyectarlos hacia los niveles de conducción local y nacional (SLyF CF, 1969-1970, p. 9).
}

No se trataba de generar intelectuales, decían, sino activistas obreros "que sirvan a los reales intereses de sus compañeros trabajadores" (SLyF CF, 1967-1968, p. s/n), y que cumplieran con determinadas características: 
queremos que la formación de estos militantes esté imbuida de una conciencia nacional, auténticamente moderna y dinámica, que permita la comunicación permanente y esclarecedora con las bases y tenga a su vez un amplio y conciso contenido humano y social... (SLyF CF, 1967-1968, p. s/n).

La formación era concebida como un derecho al que la organización debía atender, pero también como una obligación personal, y así lo expresaban al invitar a los distintos eventos: "Compañero: Es un deber de militante estar preparado y actualizado. Nuestra organización le brinda las mejores posibilidades. Inscríbase". ${ }^{47}$

A lo largo de los años se mantuvo una estructura de funcionamiento relativamente estable, aunque con una serie de modificaciones en las materias desarrolladas y el plantel docente que las dictó. La constante que atraviesa toda la experiencia del ICS, aunque con distintos énfasis, fue la preocupación por articular en la formación aspectos gremiales, socioeconómicos y también político-culturales, que tendieran a dotar de herramientas a los trabajadores para su involucramiento activo en la toma de decisiones, ya fuera en el sindicato, en su espacio laboral, o en un plano gubernamental.

Con tal fin se desplegaron una multiplicidad de instancias formativas, pero la principal -y en la que nos detendremos a seguidamente- fue el Curso Básico de Capacitación Sindical de dos años de duración. Organizado en dos niveles de cuatro a cinco meses aproximadamente cada uno, estuvo destinado a delegados, militantes y afiliados en general. En este marco, además de las materias del programa, se organizaban conferencias y mesas redondas con debates sobre problemáticas de actualidad, visitas a lugares de trabajo y proyecciones audiovisuales sobre temas políticos, sociales y económicos. ${ }^{48}$

Entre las instancias que acompañaban dicho curso, las que de alguna manera replicaban los contenidos allí desarrollados en otros espacios, se encuentran los Cursillos Intensivos que se llevaban a cabo en las distintas subsecretarías de zona. Destinados para los cuerpos de delegados o comisiones de zona, estos se planificaban de igual modo para los seis partidos. A lo largo de una semana, los docentes exponían más sintéticamente parte de los contenidos desplegados en los Cursos Básicos (SLyF CF, 1967b). Del mismo modo, las Jornadas Básicas, que surgieron en 1968 "por inquietud de los compañeros militantes para su mejor capacitación” (SLyF CF, 1969-1970), se realizaban los días sábados en jornada completa; de ellas participaban delegados y activistas. Durante los primeros años de funcionamiento del ICS también se prepararon conferencias informativas sobre temáticas coyunturales, las que se implementaban una hora antes de iniciarse las asambleas mensuales de delegados. ${ }^{49}$ Por otro lado, se implementaron cursos intensivos para delegados y cursos especiales para dirigentes gremiales, en los que se abordaban cuestiones más específicas. ${ }^{50}$ De modo complementario, algunos años para quienes habían atravesado ya el Curso Básico se realizaron cursos para egresados ${ }^{51}$ o cursillos especiales ${ }^{52}$, los que buscaban profundizar la capacitación en aspectos de la gestión y vida sindical, así como ofrecer nuevas herramientas de análisis histórico y político coyuntural.

Para la ampliación de la formación también se gestionaron becas e intercambios con otros centros de estudio. Muchas de estas, ya sea en el exterior o a nivel local, estuvieron auspiciadas por el Instituto Americano para el Desarrollo del Sindicalismo Libre (IADSL) de la AFL-CIO norteamericana, ${ }^{53}$ pero también hubo otras provenientes de instituciones académicas nacionales. ${ }^{54}$ En relación a la primera, si bien el vínculo se remonta a 1964 y abarcó distinto tipo de actividades de capacitación, desde 1966 el IADSL invitaba anualmente a uno/a o dos egresados/as del ICS a su Curso Nacional de Capacitación Sindical (SLyF CF, 1966-1967) $)^{55}$. En 1970, uno de estos estudiantes de Luz y Fuerza fue becado para realizar un curso sobre negociación colectiva en Estados Unidos, por ser el "mejor alumno" del año anterior, ${ }^{56}$ lo que muestra cierta sintonía entre ambos institutos. Reforzando estos lazos internacionales, los dirigentes participaron también de dos cursos - uno sobre Estrategia y conducción sindical y otro sobre Educación sindical- organizados por la Asociación Interamericana de Desarrollo y dictados por el Departamento de Relaciones del Trabajo de la Universidad de Puerto Rico (vinculado a la Organización Regional Interamericana de Trabajadores -ORIT). Vale la pena señalar que los dos dirigentes que viajaron en 1965 a su regreso comentaron que los cursos 
"agregaron poco al caudal que ya llevaban... pero su transcurso sirvió para dar al resto de los participantes una idea de la madurez alcanzada por el sindicalismo en la Argentina". ${ }^{57}$ Efectivamente, la publicación mensual de la ORIT relevaba elogiosamente las actividades del ICS. ${ }^{58}$

Por otro lado, y también como instancias en que se buscaba profundizar "los conocimientos recibidos" en el ICS, se apostó a la conformación de equipos de trabajo. En estos, tanto estudiantes como egresados de los cursos básicos realizaban tareas de recolección de datos a fin de elaborar distintos tipos de estudios. De esta manera, a la vez que continuaban su formación, "procuran al Sindicato información de tipo social, cultural, gremial, etc." (SLyF CF, 1965-1966, p. 18). A lo largo de los años se mantuvo esta modalidad, aunque abordando temáticas variadas. En 1966, por ejemplo, se puso en marcha un "Estudio comparativo de los Convenios Colectivos de Trabajo en vigencia" y otro sobre "Historia del movimiento obrero argentino. Importancia y rol del Sindicalismo, en relación con la macroeconomía del País y el Sistema Político (1880-1966)" (SLyF CF, 1965-1966). En 1970, otros dos sobre "Participación de los trabajadores en las decisiones de las empresas" e "Historia del Sindicato de Luz y Fuerza", ambos con la colaboración del CEES y el asesoramiento del docente Julio Neffa (SLyF CF, 1969-1970, p. 10). Para 1973, se precisan nuevos objetivos para el equipo a cargo de elaborar la memoria sindical, quienes se encargarían de

la recopilación y clasificación de datos en vistas a la concreción de una Historia del Movimiento Obrero Argentino que, escrita con mentalidad argentina y en función de los intereses propios de nuestro Ser Nacional, supere los estériles y aparentes antagonismos entre una minoría clasista seudorrevolucionaria y los personeros del sistema del vasallaje y sumisión (SLyF CF, 1973, p. 29).

Finalmente, contaron para acompañar todo este proceso con una biblioteca especializada, que a lo largo de los años fue nutriéndose con los materiales propuestos por el plantel docente. Se sumó una activa política de publicaciones, que transformó materiales didácticos -elaborados por los profesores para acompañar el dictado de las clases - en documentos que, por su relevancia y el interés que despertaban, fueron puestos a la venta. Para 1971 eran más de 20 los títulos, monografías de entre 100 y 200 páginas que circulaban entre el conjunto de los afiliados (SLyF CF, 1971, p. 27). Posteriormente, el Instituto inclusive editaría títulos que no necesariamente correspondieron a materias o cursos dictados. ${ }^{59}$

Si bien, como hemos mencionado, los distintos espacios formativos tuvieron sus destinatarios específicos, estuvieron abiertos a afiliados y activistas en general, e inclusive muchas veces apostaron a incorporar a públicos más amplios (desde miembros de otras organizaciones sindicales hasta estudiantes, pasando por las familias de los trabajadores), los cuales, en palabras del responsable del ICS, Hugo Caruso, se arrimaban "dada la seriedad y responsabilidad que ha acreditado el Instituto". ${ }^{60}$ Con ello, el SLyF apostaba a "estrechar vínculos de fraternidad" (SLyF CF, 1966-1967, p. 14) y extender el espectro de interlocutores de su "filosofía de la participación". ${ }^{61}$ Si bien esto se observa ya desde $1970,{ }^{62}$ se profundizará a partir de 1972, dado que el horizonte de sus objetivos se ampliaba. Como venía pregonando desde hacía tiempo, no serían solo los sindicatos los que requerían de dirigentes capacitados, sino el país entero "el que los necesita para hacer frente al nuevo desafío histórico, al nuevo proyecto político en que la Argentina se encuentra inmersa: el proyecto de la integración y liberación latinoamericana" (SLyF CF, 1974c, p. 6).

A continuación, nos centraremos, como indicamos, en el análisis de los Cursos Básicos de Capacitación Sindical, porque constituían la actividad más relevante que se desarrollaba desde el ICS. Para el propio sindicato estos eran "el fundamento sólido de toda la estructura del Instituto". ${ }^{63}$ La información disponible nos ha permitido reconstruir parcialmente su trayectoria a partir de $1965 .{ }^{64}$ El Curso Básico duraba dos años; se organizaba por niveles cuya duración era de cuatro meses en promedio. El cursado se efectuaba en la sede sindical de calle Perú en horario de tarde, dos veces por semana (entre cuatro/cinco horas en total ${ }^{65}$. Si bien cada ciclo fue pensado integralmente, en 1966 se introdujo la figura del alumno "libre", que habilitaba la asistencia de los alumnos a determinadas materias sin necesidad de que se realizaran el programa completo. 
Algunas de las materias que se dictaron en el primer y segundo nivel de los ciclos desarrollados durante 1965 - 1967 fueron Historia Argentina, Geografía Económica Argentina, Estructura Económica Argentina, Planificación Económica Social, Sociología, Economía Política, Historia del Movimiento Obrero Internacional, Historia del Movimiento Obrero Argentino, Estructura Social Argentina, Elementos Socioculturales de la Estructura Social Argentina, Técnicas de la Investigación Social, Industria Eléctrica, Desarrollo Eléctrico Nacional, Seguridad Social, Derecho del Trabajo, Organización Sindical, Sindicato y Política, Conducción Sindical, Organización y Funcionamiento de las Secretarías. ${ }^{66}$

Varios de los docentes de esta etapa habían compartido o lo hacían simultáneamente otras experiencias de formación relacionadas con el sindicalismo cristiano. ${ }^{67}$ Es el caso, entre otros, de Gonzalo Cárdenas, quien dictó materias como Historia Argentina o Doctrinas Sociales Comparadas (esta última junto a Arturo Almada), Julio Neffa, a cargo de Historia del Movimiento Obrero Argentino (la que luego estaría a cargo de Héctor Cordone), Oscar Martini, responsable de Estructura Económica y Planificación Económica Social, Economía Laboral o Modelos de Crecimiento Económico (esta con Floreal Forni), Atilio Borón, quien dio Estructura Social Argentina y Técnicas de la Investigación Social, Héctor Goglio, profesor de Elementos Socioculturales de la Estructura Social Argentina. Por otro lado, las materias más directamente vinculadas al quehacer político-sindical eran dictadas por los propios dirigentes de la organización, como Juan José Taccone, Luis Angeleri, Alberto Delfico, Oscar Smith, por nombrar a los más importantes. ${ }^{68}$ Esto muestra que desde un primer momento se buscó, como mencionamos, la combinación de saberes técnicos, científicos y políticos, ya fuese en los contenidos como en la complementariedad entre quienes estaban a cargo de desarrollarlos.

A partir del ciclo que arrancó en 1968 -y que mantendrá rasgos comunes hasta el Ciclo 1971- es posible identificar una serie de cambios. En el plantel docente, por un lado, y en las materias que estructuraban el Curso Básico, por otro. En cuanto al cuerpo de profesores, muchos de los mencionados más arriba dejaron de formar parte del Instituto. Las nuevas figuras que circularían por el Instituto serán: Arturo Jaureche, Rodolfo Tecera del Franco, Dardo Cúneo, Aldo Ferrer, Antonio Cafiero, entre otros. Continúan de la etapa anterior Alfonso Ferraro, Juan Maggi, Emilio Bottini, Julio Jáuregui, Belarmino Fernández. Varios de ellos tuvieron una participación más esporádica; no conformaron un grupo pedagógicamente homogéneo como el que tuvo relevancia en los años previos - de aquel grupo continúa O. Martini y regresa J. Neffa en 1969-. Entre los dirigentes sindicales que se sumaron al dictado de clases aparecen Félix Pérez, Jesús Blanco, Hugo Caruso, Vicente Montesano, entre otros.

En términos de contenidos, se redujo la cantidad de materias por año y el dictado de cada asignatura fue compartida por varios expositores. Se mantuvo un núcleo de materias vinculadas a la comprensión del proceso histórico argentino y su estructura económico-social contemporánea (Historia Argentina; Estructura Económica Argentina; Estructura Social Argentina; Estructura o Instituciones Políticas), y otras que brindaban datos y análisis sobre la coyuntura internacional (Política Internacional; Política Latinoamericana) - pero la impronta es menos sociológica y más política-. En menor medida se ofrecían herramientas teóricas (Doctrinas Sociales Comparadas en 1971 fue reemplazada por Análisis de la Doctrina Social de la Iglesia). Se preservaron las clases que remitían a su rama productiva (como Industria Eléctrica o Desarrollo Eléctrico Nacional). Se agregaron y cobraron mayor relevancia las asignaturas vinculadas al quehacer gremial (Estructura Sindical, Servicios Sociales Sindicales, Previsión Social, Derecho del Trabajo, Convenio Colectivo de Trabajo, Oratoria), y fueron menos las que atendieron a la historia o contemporaneidad del movimiento obrero en clave política (Movimiento Obrero; Sindicalismo o Conducción Sindical) ${ }^{69}$.

Si bien el contexto político cambiaría sustancialmente a partir del retorno democrático en 1973 y la identificación del SLyF con el gobierno peronista, el programa desarrollado a partir de entonces continúa los lineamientos de lo que había comenzado a impartirse desde el ciclo 1972. A partir de aquí se presenta una estructura más organizada para ambos niveles, con mayor continuidad a lo largo de los años mencionados. 
El programa para el primer nivel versaba sobre Organización sindical, Técnica de la Comunicación y Dinámica de Grupos, Historia Política, Social y Económica Argentina, Sociología y Estructuras Sociales Argentinas, Historia del Movimiento Obrero Internacional y Americano, Historia del Movimiento Obrero Argentino, Derecho del Trabajo y Previsión Social, Política Económica, Política Energética, Ciencia Política e Historia de las Ideas Políticas. Mientras tanto, durante el segundo nivel se estudiaba Economía y Planificación Social, Geografía Económica Argentina, Estructura Económica Argentina, Estructuras Políticas Argentinas, Política Internacional y Latinoamericana, Seguridad Industrial, Industria y Desarrollo Eléctrico, Conducción Sindical; Participación, Cogestión, Autogestión.

Como se puede observar, era un programa extenso y ambicioso, ${ }^{70}$ en el que se retoma la impronta de los primeros años en lo que refiere al interés por una formación más económico-social y no tan sindical, quizá ahora con una identidad latinoamericanista más clara -sobre todo en el Ciclo 1974 que explícitamente postulaba la importancia de capacitarse en la conducción "dentro del enfoque de la integración continental (SLyF CF, 1974c, p. 6) ${ }^{71}$-. En este también se nota que la cuestión de la "dependencia" (fundamentalmente en clave económica) fue transversal a todo el programa en ambos niveles.

Por otro lado, el énfasis puesto en la formación ideológica es ahora explícito a través de materias como Teoría Política General y Doctrina Justicialista. Anteriormente -aunque fuera del programa ordinario- se había realizado un curso de actualización doctrinaria y actualización política, destinado a cuadros "políticos, técnicos y sindicales". Organizado en conjunto con el Comando Tecnológico Peronista (CTP), su dictado estuvo a cargo de Julián Licastro. ${ }^{72}$ Un año después se llevó a cabo una actividad "de actualización” similar, pero destinada a dirigentes gremiales, por un lado, y a delegados y activistas, por otro. ${ }^{73}$

Finalmente, de la mano del proceso de autogestión iniciado en SEGBA a partir de 1973, en esta etapa se retomó con fuerza el desarrollo de aquellas temáticas vinculadas a la participación de los trabajadores. Recordemos que estas habían tenido una importancia significativa entre 1965 y 1967, con materias que colocaban la cuestión más directamente en relación con la planificación económico-social -con una materia homónima y de modo puntual en otras como Industria Eléctrica, Estructura Social Argentina, o Modelos de Crecimiento Económico (SLyF CF, 1967a)-, pero que a partir del ciclo 1968 perderían espacio y sistematicidad en el ámbito de la formación. Ahora reaparece directamente articulada al ámbito de la empresa, y más específicamente atada a la discusión sobre modelos de gestión. Destaquemos a su vez que el área Participación, Cogestión, Autogestión, que no figuraba en el programa de 1972, pasó de ser un seminario intensivo de un día en 1973 -en el que se trataban los puntos: "Participación. Cogestión. Autogestión. Socialismo Nacional"-, a dos materias con un extenso programa, dictadas respectivamente en cada uno de los niveles planificados en 1974 (SLyF CF, 1973, p. 37; 1974c). No por casualidad se anunció que este ciclo había sido estructurado "en torno al tema central 'La participación de los trabajadores"” (SLyF CF, 1974c, p. 10).

Si bien no contamos con datos precisos sobre el alcance o grado de participación de los trabajadores lucifuercistas en el conjunto de las actividades del Instituto, el propio sindicato estimaba que desde sus orígenes hasta 1974 habían pasado por las mismas "15.000 compañeros" (SLyF CF, 1974e, p. s/n). La cifra resulta algo elevada si consideramos que, en 1965, por ejemplo, egresaron del primer nivel del Curso Básico 21 varones y 2 mujeres, mientras que del segundo nivel lo hicieron solo 14 varones. En 1966, 31 y 15 respectivamente (con una mujer en cada caso); 33 y 25 al año siguiente (la fuente no permite distinguir sexo); 24 y 22 (de las cuales 2 fueron mujeres) en $1968 .{ }^{74}$ En los casos en que es posible contar con el dato de inscriptos es llamativa la deserción (sobre todo en el primer nivel). Para el ciclo 1973 hablaban de "la mayor afluencia de alumnos conocida en los trece años de vida de nuestro Instituto" ${ }^{75} \mathrm{Si}$ bien la cantidad de egresados no varía sustancialmente ( 45 en el primer nivel y 18 en el segundo), sí cabe señalar el aumento porcentual de mujeres: $25 \%$ y $20 \%$ respectivamente. ${ }^{76} \mathrm{Al}$ año siguiente, quienes recibieron sus certificados de finalización fueron 73 y 31 en cada nivel, entre ellos, la participacion femenina osciló el 33 \% (18 y 8 respectivamente) $)^{77}$. 
Las actividades acotadas en tiempo y temática tuvieron una participación mucho mayor. Es el caso de los cursillos intensivos o especiales: en 1967 el que analizaba el Convenio Colectivo de Trabajo contó con 50 asistentes -al igual que al año siguiente- y el que se dedicó a analizar la estructura y funcionamiento de las secretarías del sindicato, 150, entre alumnos del curso básico, delegados y afiliados (SLyF CF, 1967-1968). Ese mismo año, el ciclo abierto de conferencias con debate contó con 300 participantes, y las proyecciones del ciclo de cine sobre problemas sociales y gremiales, organizadas junto con el Cine-Club, congregaron a 200 asistentes, entre alumnos, delegados y afiliados. Las actividades desarrolladas en cada subsecretaría de zona (de las que participaban delegados, subdelegados, representantes de cada subcomisión y activistas) sumaban en promedio 50 asistentes por localidad por semana (SLyF CF, 1967-1968).

A las Jornadas Básicas que se realizaron a fines de 1969 en el Hogar del Niño de la Villa Olímpica de Morón asistieron unas 300 personas y 360 en 1970 (los datos representan el total de los encuentros) ${ }^{78}$. Los números disponibles para 1973 indican que se realizaron 4 cursos intensivos para delegados, con 260 participantes; 3 para dirigentes, a los que fueron 450 cuadros de distinto nivel; y 3 Jornadas básicas a las que concurrieron 500 personas (SLyF CF, 1974b). En 1974 se estableció una modalidad novedosa para este último tipo de actividades, que incorporaba a las familias de los afiliados a las mismas, bajo el argumento de la importancia que revestía "la participación total del ámbito familiar del trabajador en el actual proceso de capacitación para la reconstrucción nacional". ${ }^{79} \mathrm{El}$ saldo había sido una muy nutrida y "entusiasta" concurrencia. ${ }^{80}$

Así, la formación política, si bien pensada de modo prioritario para el militante sindical, no excluía a la "gran familia que es Luz y Fuerza" ${ }^{81}$ Esta no solo era beneficiaria de cursos y actividades que tendían a una promoción cultural general, como vimos en el apartado anterior, sino también convocada a asumir la responsabilidad de la participación. Del mismo modo, y como veremos a continuación, el SLyF imaginó una propuesta educativa para el movimiento obrero de conjunto.

\section{FÁbricAS Y SINDICATOS COMO AULAS: HACIA LA UNIVERSIDAD SINDICAL}

En sintonía con su mirada integral sobre educación obrera y en la coyuntura política abierta a partir de 1973, el SLyF elaboró una propuesta "educativa-sindical" que, afirmaban, "no puede ser sino la preparación concreta [del movimiento obrero] para la conducción de ese mismo proceso liberador" (SLyF CF, 1974b, p. 43). Este gremio aportaba a la CGT -en tanto máximo órgano de representación del sindicalismo a nivel nacional- un proyecto de "universidad de los trabajadores, para los trabajadores", basado en su propia experiencia en la materia. Se lo concibió "como un sistema de educación que posibilita la capacitación de los trabajadores agremiados, tanto en relación con las tareas o trabajos que cumplen diariamente, o para los que se preparan, como la capacitación para la actuación y la conducción gremial" (SLyF CF, 1974d, p. 33 -resaltado en original-).

Ya fuese en el plano sindical o laboral, el proceso de formación se sustentaba sobre la práctica de los sujetos. En sus palabras, la Universidad Sindical -que no pretendía reemplazar a la Tecnológica- se caracterizaría por ser un organismo

que posibilite la capacitación y consolide la formación fundamentalmente a través del reconocimiento del saber de los trabajadores, adquirido en el trabajo, verificado en el trabajo y completado o perfeccionado sobre y a partir del mismo trabajo, por la acción directa de las organizaciones sindicales (SLyF CF, 1974d, p. 33 -resaltado en original-).

En concreto, la validación de los saberes prácticos del trabajador abarcaba dos aspectos:

el técnico, consiste en el perfeccionamiento y reconocimiento de los saberes profesionales, y el gremial, consistente en la capacitación y en el reconocimiento de las capacidades para la conducción gremial, sea para actuar en el nivel nacional, como en el latinoamericano (SLyF CF, 1974d, p. 34 -resaltado en original-). 
¿Dónde y cómo se llevaría adelante esto? Proponían una estructura en la cual la CGT cumpliría las funciones de un rectorado, los sindicatos ocuparían el nivel de las facultades/departamentos, mientras que los ámbitos de trabajo o sindicatos se equiparaban al espacio áulico. De allí que el título a otorgar "no es más que el reconocimiento del cargo ocupado o del nivel del saber adquirido por el trabajador, para desempeñar una tarea profesional o técnica, o de actuación o conducción gremial” (SLyF CF, 1974d, p. 34).

La educación era entendida como un "proceso de liberación individual y social" (SLyF CF, 1974d, p. 34), sobre todo si el trabajo era utilizado como instrumento educador. Este constituía el basamento de la educación, por ello no se trataba de crear una nueva institución, sino de reconocer lo que ya se hacía en gremios o fábricas. Esta concepción hacía de la universidad una institución "abierta", "exclaustrada", que no remitía a un recinto sino a "programas y tareas de aprendizaje, estimuladas y luego reconocidas por la dirección del movimiento obrero" (SLyF CF, 1974d, pp. 34-35 -resaltado en original-) $)^{82}$.

En el camino de conformar esta Universidad Sindical, proponían crear el Instituto de Altos Estudios Sindicales (IDAES) de la CGT. Su función sería "formar a los trabajadores para la conducción gremial y para su participación en las decisiones empresarias y del Estado" (SLyF CF, 1974b, p. 43). También de extensión nacional, la CGT funcionaría como rectorado y sus regionales como organismos descentralizados, mientras que los sindicatos actuarían como organismos de ejecución.

Para esta "etapa experimental", hacia la Universidad Sindical que representaba el IDAES, sugerían implementar tres programas: el Curso Superior de Formación Sindical, ${ }^{83}$ el Curso Especial para Agregado Obrero, ${ }^{84}$ y el Curso Intensivo para Dirigentes. ${ }^{85} \mathrm{Si}$, como denunciaban, "lamentablemente las universidades nacionales, por su cuño individualista liberal, se han caracterizado por formar 'patrones”, correspondía a la CGT "formar, como técnicos y profesionales, a miembros de sus propias organizaciones pero no para que se alejen de ellas" ${ }^{86}$ Recordemos que esta propuesta engarzaba con el llamado del entonces presidente J. D. Perón a volver a poner en marcha las escuelas sindicales inauguradas durante su primer gobierno, por cuanto se necesitaban "dirigentes altamente capacitados" ${ }^{87}$

Cabe señalar que, en sintonía con su aproximación integral a la cuestión educativa, la propuesta de Universidad Sindical se sustentaba en una mirada abarcadora sobre el sistema argentino. En un sentido general, se criticaba la "trampa" de la escolarización, que, nacida para igualar y democratizar, generaba diferencias e injusticias. "La escuela es un banco, y el saber acreditado es capital” (SLyF CF, 1974d, p. 18), que premia falsos saberes y genera desigualdades de poder, sostenían. La nueva estructura que proponían aparecía directamente "vinculada al trabajo" a partir de los 16 años y suponía que trabajar ya es estudiar. De allí que, entendiendo que la idoneidad era prueba del saber, no debían exigirse certificados previos ni otorgarse títulos. Como vimos, en este esquema la Universidad no era un lugar sino "un programa de aprendizaje" que se cumple en distintos espacios.

Finalmente, es importante apuntar que, así como desde un primer momento se apeló al asesoramiento y acompañamiento de cuadros técnicos en distintas materias, aquí también se procuró el trabajo en conjunto con especialistas. En el caso de la educación fue Gustavo Cirigliano ${ }^{88}$ quien colaboró en la producción de una serie de materiales que, por un lado, sistematizaron el recorrido trazado por el sindicato, pero que, a la par, formulaban una serie de lineamientos y sugerencias. En estos folletos se explicitaba que su elaboración había sido resultado de charlas y documentos desarrollados en el marco de los cursos de formación sindical del ciclo 1973. Reaparece, así, la concepción en torno a la construcción conjunta de conocimientos entre trabajadores y expertos, y la valoración que el SLyF hacía de su rol -de ningún modo subordinado- en dicha relación. Mientras recurrían a los aportes de aquellos, se prepararían ellos mismos como técnicos y profesionales en una universidad de los trabajadores y para los trabajadores. 


\section{REFLEXIONES FINALES}

El grupo que condujo al sindicato en los años sesenta y setenta compartió un conjunto de definiciones acerca del poder y del lugar -central- de los sindicatos en la organización social deseada. Como parte de la construcción de dicho proyecto debe ubicarse la preocupación por la educación obrera, y puede comprenderse el lugar estratégico que le otorgaron. De allí que el SLyF asumiera un rol de avanzada como impulsor de diversas instancias de formación hacia su sector, aunque interesado cada vez más en amplificar el espectro de interlocutores, a fin de confluir con otros actores sociales y trabajadores de otras ramas para difundir su "filosofía de la participación". Buscó entonces anudar las tareas específicas de formación con el objetivo primordial perseguido: lograr la participación de los trabajadores -en los ámbitos de gestión empresarial y de poder estatal, pero también en otras esferas de la vida social, incluyendo, por supuesto, la gremial-, ya que era esta práctica formativa la que podía garantizar que "sindicalismo múltiple y participación integral, para Luz y Fuerza, no [fueran] simples postulados teóricos" ${ }^{89}$

Así entraba a jugar la formación político-sindical, por cuanto trabajadores y dirigentes debían capacitarse a fin de contar con las herramientas adecuadas para discutir y exigir la mencionada participación. Vimos la atención dedicada a la preparación de activistas, delegados y cuadros de distinto nivel, a través de la puesta en circulación contenidos técnicos y políticos. Para este fin se programaron un sinfín de cursos, seminarios y encuentros desde la creación del ICS en 1962. Pero a la par es posible advertir cómo, justamente por esa concepción integral sobre el vínculo trabajadores/poder, se fue construyendo una mirada más abarcadora en torno a lo educativo, que los llevó a reflexionar sobre el sistema formal existente en la Argentina y proponer reformulaciones basadas en el trabajo como eje organizador del mismo. Su propia concepción acerca del lugar que las organizaciones sindicales debían desempeñar en la sociedad los condujo a articular un proyecto pedagógico en el que entraron desde eventos de formación político-sindical clásicos, actividades de capacitación vocacional y/o profesional, la creación de instancias de escolarización formal para la educación de adultos, hasta un conjunto de espacios culturales y recreativos destinados al colectivo más amplio de trabajadores y a la familia obrera.

Como sugeríamos al inicio, la entrada a los años sesenta y setenta, a través de un tipo de práctica sindical que ha sido poco atendida, nos permite -aun como líneas a seguir indagando-formular una serie de interrogantes a los abordajes historiográficos sobre el período, más bien preocupados por reponer las experiencias de un sindicalismo combativo o clasista, cuya característica nodal fue la democracia sindical y la constante movilización de sus bases. Pero, si enfatizásemos las formas y no los contenidos de la práctica sindical perspectiva que suele deslizarse en muchos trabajos sobre la época-, podríamos afirmar que el SLyF, tildado de "participacionista" y "burocrático", y siempre puesto en oposición con su par cordobés, estaría mostrando una estrategia que buscaba, a través de la formación de sus trabajadores, activistas y cuadros, no solo promover la participación interna sino también acrecentar el plantel dirigencial de la organización (en cantidad y calidad) para que estos se proyectasen más allá del ámbito gremial. Entonces, si lo que importaba -y definía a un gremio clasista / combativo- era la generación de espacios de involucramiento de las bases sindicales, ¿qué hacer con un sindicato como Luz y Fuerza Capital, que defendía la participación más allá del ámbito formal de la asamblea o la organización en el piso de trabajo?, ¿cómo ubicarlo en los esquemas dicotómicos trazados para la época?, ¿ ¡podríamos equipar, o al menos espejar, sindicalismo múltiple con sindicalismo de liberación?

El caso analizado da cuenta de los problemas que acarrea para la interpretación histórica este esquema interpretativo que reduce el análisis a los mecanismos de la participación, cuando se deja de mirar a los gremios combativos y, en cambio, se ubica el foco en los sectores reformistas. El cruce analítico, entonces, debería buscarse no en aspectos formales (entre participación y el incremento de las instancias de toma de decisiones), sino de fondo (entre participación y autonomía/heteronomía de clase -con todas sus posibilidades intermedias-). En definitiva, se trata de quiénes y cómo, pero también de con qué insumos y horizontes se toman las decisiones. Así aparece más claramente la bifurcación de caminos y estrategias obreras. 
De allí la relevancia de prestar atención a los espacios de formación sindical y de educación obrera en general, por cuanto, si son entendidos como instancias constitutivas de la dinámica conflictual, permiten discernir la direccionalidad que se le pretende dar a determinados procesos en curso, el sentido y metas de las luchas obreras. En esta clave, la nota distintiva del SLyF fue que no dejó nada librado a la espontánea interpretación de las masas, por el contrario, procuró poner su impronta a la conflictividad del período a través de una formación metódica y sistematizada.

\section{REFERENCIAS}

Altamirano, C. (1998). Desarrollo y desarrollistas. Prismas. Revista de historia intelectual, 2, 75-94.

Angeleri, L. (1979). Los sindicatos argentinos son poder. Buenos Aires: Pleamar.

Balve, B. (1990). Los nucleamientos político-ideológicos de la clase obrera. Composición interna y alineamientos sindicales en relación a gobiernos y partidos. Argentina, 1955-1974. Buenos Aires: CICSO Serie Estudios No 51.

Baraldo, N. (2020). Movimiento obrero y educación. Sentidos y estrategias en torno a los Centros Educativos de Nivel Secundario. Argentina, 1970-1974.Trabajo y sociedad, XXI, 179-198.

Baraldo, N. (2016). Escuela media, conocimiento y trabajadores. Los CENS de la DINEA en los '70s. Polifonías Revista de Educación, $V(9), 178-202$.

Belloni Ravest, H. (1973). Educación sindical en la Argentina. Experiencias sobre capacitación obrera en España y Francia. Buenos Aires: S/Ed.

Dawyd, D. (2012). El nuevo autoritarismo burocrático y el sindicalismo peronista. Análisis de la "participación” junto al gobierno militar de Onganía en la Argentina de los años sesenta: del "nuevo orden social" al "Cordobazo". Confluenza, 4(2), 17-44.

Fernández, A. (1986). Ideologías de los grupos dirigentes sindicales (1966-1973), tomo 2. Buenos Aires: CEAL.

Ghigliani, P. (2012). La resistencia de Luz y Fuerza a las políticas de la dictadura: los conflictos de 1976 y 1977 . Historia Regional, 25(30), 51-71.

Ghigliani, P. (2009). Los dilemas de la democracia sindical: la Federación Gráfica Bonaerense 1966-1975. En A. Belkin (Comp.), Relatos de luchas: Contribuciones a la historia del movimiento obrero (pp. 91-115). Buenos Aires: Desde el Subte.

Ghigliani, P., y Grigera, J. (2011). El sindicalismo empresario en perspectiva socio-histórica: hipótesis de trabajo. Trabajo presentado en VI Jornadas de Estudios Sociales de la Economía. UNSAM, Buenos Aires.

Giorgi, G. (2015). En los pliegues de la planificación del Onganiato: el comunitarismo como política estatal (1966-1970). Anuario IEHS, 29/30, 159-175.

Grau, M. I. (2007). Análisis de la organización de los trabajadores de la producción de energía eléctrica: del "sindicalismo de participación" al "sindicalismo empresario". Trabajo presentado en XI Jornadas Interescuelas/Departamentos de Historia. Facultad de Filosofía y Letras UNT, San Miguel de Tucumán.

Graziano, R. (1989). La gestión sindical en Segba. Buenos Aires: CEAL.

Haidar, J. (2017). El estudio de la economía gremial: el caso del sindicato argentino Luz y Fuerza Capital Federal (1943-2003). Espiral: Estudios sobre Estado y Sociedad, XXIV(70), 137-179. Recuperado de https://dialnet.uni rioja.es/servlet/articulo?codigo $=6274531$

Iturraspe, F. (1986). Participación, cogestión y autogestión en América Latina. Caracas: Ed. Nueva Sociedad.

Lida, M. (2012). Catolicismo y sensibilidad antiburguesa. La Iglesia Católica en una era de desarrollo, 1955-1965. Quinto Sol, 16(2), 1-20.

Neffa, J. C. (1971). La participación interna de los sindicatos en Argentina. Estudio del Sindicato Luzy Fuerza de Capital Federal. Ginebra: IIEL-OIT (documento interno).

Pronko, M. (2003). Universidades del trabajo en Argentina y Brasil: una historia de las propuestas de su creación; entre el mito y el olvido. Montevideo: CINTERFOR. 
Rodríguez García, M. (2010). Liberal Workers of the World, Unite? The ICFTU and the Defence of Labour Liberalism in Europe and Latin America (1949-1969). Oxford: Peter Lang.

Scodeller, G. (2015). En búsqueda de un sindicalismo 'moderno': reformismo sindical y formación política en los años sesenta en Argentina. Nuevo Mundo - Mundos Nuevos. Buenos Aires.

Scodeller, G. (2013a). El Instituto de Capacitación y Formación Social Sindical: una experiencia de formación políticosindical en un contexto de intensa conflictividad social (Argentina, 1963-1965). Mundos do Trabalho, 5(9), 239-258.

Scodeller, G. (2013b). La formación político-sindical de los trabajadores socialcristianos en la Argentina de los años '60. Anuario del Centro de Estudios Históricos Carlos Segreti, 11(11), 303-321.

Selser, J. (1970). Participación de los trabajadores en la gestión económica. Buenos Aires: Ediciones Libera.

Silva Gotay, S. (1981). El pensamiento cristiano revolucionario en América Latina y el Caribe. Salamanca: Ed. Sígueme.

Sindicato Luz y Fuerza Capital Federa [SLyF CF] (1965-1966). Memoria y Balance, julio 1965 - junio 1966. Buenos Aires: Sindicato Luz y Fuerza Capital Federal.

Sindicato Luz y Fuerza Capital Federa [SLyF CF] (1966-1967). Memoria, julio 1966 - junio 1967. Buenos Aires: Sindicato Luz y Fuerza Capital Federal.

Sindicato Luz y Fuerza Capital Federa [SLyF CF] (1967a). Instituto de Capacitación Sindical. Buenos Aires: Secretaría de Cultura.

Sindicato Luz y Fuerza Capital Federa [SLyF CF] (1967b). Instituto de Capacitación Sindical. Ciclo de estudio semanal especialmente programado para las Subsecretarias de zonas. Buenos Aires: Secretaría de Cultura.

Sindicato Luz y Fuerza Capital Federa [SLyF CF] (1967-1968). Memoria y Balance, julio 1967 - junio 1968. Buenos Aires: Sindicato Luz y Fuerza Capital Federal.

Sindicato Luz y Fuerza Capital Federa [SLyF CF] (1969-1979). Memoria y Balance, julio 1969 - junio 1970. Buenos Aires: Sindicato Luz y Fuerza Capital Federal.

Sindicato Luz y Fuerza Capital Federa [SLyF CF] (1970-1971). Memoria y Balance, julio 1970 - junio 1971. Buenos Aires: Sindicato Luz y Fuerza Capital Federal.

Sindicato Luz y Fuerza Capital Federa [SLyF CF] (1971). Instituto de Capacitación Sindical. Buenos Aires: Secretaría de Cultura.

Sindicato Luz y Fuerza Capital Federa [SLyF CF] (1972a). Escuela Nacional de Educación Media para Adultos. Buenos Aires: Sindicato Luz y Fuerza Capital Federal.

Sindicato Luz y Fuerza Capital Federa [SLyF CF] (1972b). Pautas para una politica nacional. Buenos Aires: Ed. 2 de Octubre.

Sindicato Luz y Fuerza Capital Federa [SLyF CF] (1973). Instituto de Capacitación Sindical. Buenos Aires: Secretaría de Cultura.

Sindicato Luz y Fuerza Capital Federa [SLyF CF] (1974a). Bachillerato especializado para adultos. Buenos Aires: Secretaría de Cultura.

Sindicato Luz y Fuerza Capital Federa [SLyF CF] (1974b). Educación sindical. Bs. As.: Secretaría de Cultura, Serie Apuntes para trabajar.

Sindicato Luz y Fuerza Capital Federa [SLyF CF] (1974c). Instituto de Capacitación Sindical. Educación sindical para la reconstrucción nacional. Buenos Aires: Secretaría de Cultura.

Sindicato Luz y Fuerza Capital Federa [SLyF CF] (1974d). La nueva educación argentina. Buenos Aires: Secretaría de Cultura, Serie Apuntes para trabajar.

Sindicato Luz y Fuerza Capital Federa [SLyF CF] (1974e). Cultura y Deporte en Luzy Fuerza. Buenos Aires: Secretaría de Cultura.

Taccone, J. J. (1976). 900 Días de Autogestión en Segba. Una experiencia argentina de participación. Buenos Aires: Fundación 2001.

Taccone, J. J. (1971). Crisis... respuesta sindical. Buenos Aires: Editorial Delta. 
Zanca, J. (2012). ¿Primos o hermanos? Nacionalismo, integralismo y humanismo cristiano en la Argentina de los años sesenta. Amnis, 11, 1-9.

Zanca, J (2006). Los intelectuales católicos y el fin de la cristiandad: 1955-1966. Buenos Aires: FCE.

\section{Notas}

1 La cita del título corresponde al discurso del entonces Secretario de Cultura Hugo Caruso, 20/12/73 (SLyF CF, 1974a, p. 5).

2 La caracterización pretende ubicar al sindicato argentino en el concierto latinoamericano y mundial, ya que su preocupación por la participación es parte de un debate que supera las fronteras nacionales, ejercicio que posibilita complejizar ciertas apreciaciones que circulan en la bibliografía secundaria sobre la corriente sindical que analizaremos. En este sentido, Luz y Fuerza entroncaba con los planteos contemporáneos referidos al proceso de modernización para la región propios del horizonte reformista que amalgamó la Carta de Punta del Este (agosto 1961) -documento que delineó los objetivos de la Alianza para el Progreso-. Recordemos que ésta -la vía de la "revolución pacífica" tal como el propio J. F. Kennedy la definió-, y antes la Revolución Cubana, habían actualizado el problema del atraso de la región, planteando la solución como reforma o como revolución social respectivamente. Véase Scodeller (2015).

3 Luz y Fuerza constituye una primera experiencia que abona nuestra hipótesis, aunque el estudio no pretende saldarse en estas páginas, ya que requiere del abordaje de otros casos, tanto del campo reformista como revolucionario.

4 Sindicato Luz y Fuerza Capital Federal y Archivo personal de Hugo Caruso, Biblioteca Eva Perón de la Confederación General del Trabajo, Biblioteca Nacional de Maestros, Centro de Documentación e Investigación de la Cultura de Izquierdas, Centro de Documentación e Investigación acerca del Peronismo -todos en Ciudad Autónoma de Buenos Aires-, Instituto Ibero Americano de Berlín, Instituto Internacional de Historia Social y Centro de Estudios y Documentación Latinoamericanos, ambos en Amsterdam.

5 Para 1971 contaba con 27.000 afiliados activos -además de 7.000 jubilados y pensionados-, que rondaban los 30.000 cinco años después (Taccone, 1971, pp. 75-76; 1976, p. 53).

6 Para un análisis pormenorizado de los mecanismos de reproducción material del sindicato entre 1943 y 1976 , caracterizado como un período de expansión material, véase Haidar (2017, pp. 148-154).

7 La década del sesenta encontró al SLyF conformando el nucleamiento de los Independientes primero y luego el de los No Alineados. Se retiró de la CGT con la división de 1968 y recién volvería a participar de la misma con el proceso de normalización de la central obrera que se inició a fines de 1969, integrando a partir de 1970 -y desde el año siguiente en adelante dentro de las 62 Organizaciones- sus cuerpos directivos (Balvé, 1990).

8 Si la participación sindical fue una cuestión que atravesó las agendas de organismos (inter)gubernamentales e (inter)nacionales desde la segunda posguerra, es importante mencionar que en Argentina el gobierno de la autodenominada "Revolución Argentina" en su primera etapa promovió una participación en clave autoritaria, entendiendo que era un mecanismo para lograr consensos y encausar demandas que no encontraban otras vías formales de expresión. Pero en el esquema comunitarista-corporativista los espacios y dispositivos eran pensados y aplicados de manera acotada, limitándose a la búsqueda de asesoramiento técnico, es decir, que no implicaban una real participación en los ámbitos de decisión, ejecución ni control de políticas, como demandaban ciertas organizaciones sindicales. De allí las frustraciones y posterior alejamiento de la dirigencia lucifuercista con el gobierno de J. C. Onganía, en quien habían depositado inicialmente sus esperanzas. $\mathrm{Al}$ respecto de las tensiones al interior del proyecto del onganiato, véase Giorgi (2015).

9 Como tantos otros, este sindicato vio con buenos ojos el golpe de 1966, aunque tuvo mayores expectativas en dicho gobierno y vínculos con el sector nacionalista católico - las cuales se deterioraron a medida que avanzó el sector liberal al cual criticaban-.

10 Según Selser, el SLyF era, consumado en la figura de los directores obreros, el único ejemplo de participación en empresas estatales vigente en Argentina a fines de los sesenta (1970, p. 76). Para referencias sobre otras experiencias nacionales y mundiales pasadas y contemporáneas, véase Graziano (1989), Iturraspe (1986) y Selser (1970).

11 Su formulación acabada puede verse en SLyF CF (1972b). Volveremos sobre esta publicación.

12 SLyF CF, Revista Dinamis, Año IV N³7, Buenos Aires, octubre 1971, p. 85.

13 Revista Dinamis, Año IV N³7, octubre 1971, p. 84.

14 Las referencias a las encíclicas de Juan XXIII y Pablo VI o a la Comunidad Organizada de J. D. Perón se repiten insistentemente en numerosos escritos sindicales y notas en la Revista Dinamis. Al respecto se pueden consultar los desarrollos teórico-políticos elaborados por sus principales referentes, Juan José Taccone (1971; 1976) y Luis Angeleri (1970). Graziano (1989, p. 72) advierte que el núcleo doctrinario del peronismo es anterior a las encíclicas papales posconciliares que incorporan al primero la cogestión como mecanismo para superar el conflicto entre las clases. Por 
ello, según el autor, no se habrían manifestado demandas de participación durante el peronismo clásico -articulado en torno a las encíclicas preconciliares-.

15 Las concepciones y esquemas con que se pensó y formuló la participación sindical desde la política, la religión y el mundo del trabajo fueron muy diversas a lo largo del siglo XX. Pero en el contexto de creciente conflictividad política y social de los años sesenta y setenta existe cierto consenso - patrocinado y puesto en circulación por la Organización Internacional del Trabajo (OIT) - en torno a la ampliación de los canales de participación de los trabajadores en la toma de decisiones como mecanismo para resolver o anular los conflictos, vale decir, como garantía de control sobre la efervescencia laboral fuera de las fábricas y de gestión de la mano de obra dentro de las mismas.

16 SLyF CF, Dinamis Quincenal, Año III N¹87, Buenos Aires, 04/06/1969, p. 17.

17 Aún esperanzados en la alianza entre movimiento obrero y fuerzas armadas, las críticas al régimen militar eran tibias y apuntaban al alejamiento de su cauce original a causa de la presión ejercida por los sectores liberales. En este sentido por ejemplo, defendían a los equipos de trabajo de Onganía, a quienes a su entender se los habría neutralizado a través de una campaña mediática que identificó conceptos como comunitarismo y comunidad con fines totalitarios (Dinamis, $\mathrm{N}^{\circ} 142$, abril 1968, p. 7) -estas posiciones divergentes existían dentro del propio gobierno y remitían a distintas líneas católicas (Giorgi, 2012, p.166)-. Así, el SLyF negaban que el debate de la hora fuese "democracia-corporativismo" afirmando que “el país exige Revolución Nacional con participación” (Dinamis, N 137, noviembre 1967, p. 4). Inclusive -o quizá debido al mismo-, en el contexto de ebullición político-social post Cordobazo, refuerzan aquellas nociones constitutivas de su identidad (peronista y cristiana) afirmando -en relación al plano educativo- que: "Los momentos actuales exigen más que nunca de la capacitación y ésta tiende a elevar a los trabajadores a los planos del saber y la cultura. Los frutos de ella estimularán las iniciativas y los esfuerzos para que con su aporte se engrandezca la obra común que tiene como base la lucha por la JUSTICIA SOCIAL, por la dignidad humana del hombre y por la solidaridad que constituyen los pilares sobre los que se constituirá una verdadera comunidad feliz" (Dinamis Quincenal, Año IV N¹76, 29/10/1969, p. 37 -resaltado en original-).

18 "Nadie debe equivocarse: los únicos capaces de encabezar una revolución nacional y cristiana somos los trabajadores". Dinamis Quincenal, Año V N²02, 29/07/1971, p. 4. También en 1974 se arengaba a seguir avanzando "en la defensa de aquellos valores nacionales y cristianos que son la razón misma de nuestro existir y de nuestro obrar” (SLyF CF, 1974c, p. 33).

19 Ya reconociendo el descrédito en que habían caído las Fuerzas Armadas y llamando al movimiento obrero a pronunciarse a favor de la institucionalización del país, por un "gobierno popular" sin el cual "no habrá soluciones posibles" (Dinamis, Año IV N46, julio 1972), uno de los editoriales referido a las elecciones concluía diciendo: "Que nadie se equivoque. La única opción válida es LIBERACION o DEPENDENCIA” (Dinamis Interno, Año VII N²20, Buenos Aires, 22/02/73, p. 4 -resaltado en original-). En términos educativos, ahora consustanciados con el gobierno peronista que asume en 1973 e identificados con el "proceso ineludible de la Reconstrucción Nacional” (SLyFCF, Dinamis Interno, Año VII N²21, Buenos Aires, 11/04/73, p. 28) en su variante a favor del socialismo nacional, expresaban: "De allí la importancia de nuestro Instituto de Capacitación Sindical, no sólo para Luz y Fuerza sino para el Movimiento Obrero en general, cuando la tarea fundamental consiste en la creación de una auténtica conciencia nacional que rescate los valores de dignidad de la persona humana y del trabajo como su más alta manifestación. Solamente así será posible la construcción de un Socialismo Nacional que ubique al hombre en su verdadera dimensión social y culmine la lucha del Pueblo por su Liberación” (SLyF CF, 1973, p. 7).

20 Entre otro de los varios ejemplos que pueden citarse, el siguiente párrafo refuerza dicha idea: "No cabe duda que la educación de los trabajadores a nivel Sindical, juega un papel primordial en el cual los Sindicatos tienen obligación moral y espiritual de cumplir, a efectos de poder desarrollar la actividad gremial con militantes que están en un nivel óptimo de condiciones que permitan efectuar una actividad múltiple y planificada, adecuada a la época contemporánea de este mundo moderno en que vivimos" (SLyF CF, 1967-1968 -el resaltado es nuestro-).

21 Revista Dinamis, $\mathrm{N}^{\circ} 136$, octubre 1967, p. 30.

22 "Indudablemente la capacitación cumple en el movimiento obrero un rol importante, que permite por medio del estudio de las Ciencias Sociales un esclarecimiento total y actualizado, que luego se efectiviza en la conducción y dirección de sus cuadros orgánicos" (SLyF CF, 1971, p. 6).

23 Véase las Memorias y Balances correspondientes a los años 1969-1970 y 1970-1971, Dinamis Quincenal, Año IV N ${ }^{\circ} 178$, 3/12/69 y N¹79, 17/12/69, entre otros. Algunos resultados del mismo pueden consultarse en Neffa (1971).

24 Revista Dinamis, N¹37, noviembre 1967.

25 Ídem.

26 Dinamis Interno, Año VII N²19, 18/01/73, p. 12. Se trata de una reproducción de la entrevista realizada por el semanario Siete Días y originalmente publicada bajo el título "Un programa en busca de partido".

27 Dinamis Interno, Año VII No219, 18/01/73, p. 12.

28 Dinamis Quincenal, Año V N²05, 27/10/1971. 
29 Inclusive se pensó en la realización de un film sobre la historia del sindicato, del cual estuvo a cargo Hugo del Carril. Véase entrevista al director en Revista Dinamis, Año XXI N92, 06/05/1965.

30 Véase también Dinamis Quincenal, Año XXII N¹19, 28/07/1966 y Año III N²146, 07/1968.

31 Revista Dinamis, N¹36, octubre 1967.

32 Dinamis Quincenal, Año IV Nº186, 20/05/1970, p. 10.

$33 \mathrm{Si}$ atendemos a las encíclicas a las que los máximos referentes de LyF remiten sus argumentaciones (Mater et Magistra, Populorum Progressio, e inclusive los documentos finales de la II Conferencia del Episcopado Latinoamericano) sobre todo como fundamento de la participación, debemos decir que se trata de la versión posconciliar -en su línea reformista (Silva Gotay, 1981, pp. 37-49)-; aunque sus alineamientos políticos empalmen con los principios más conservadores organicista-paternalistas y corporativistas (Pronko, 2003, p. 34) - que caracterizan a las preconciliares (Rerum Novarum y Quadragésimo Anno). Dada, además, la importancia que los lucifuercistas otorgaban al conocimiento proveniente de las ciencias sociales, dialogaron con varios intelectuales del humanismo cristiano -en particular el padre Alberto Sily referente del Centro de Investigación y Acción Social (CIAS)-, interesados en la imbricación de estos con dichas áreas disciplinares (Zanca, 2006, p. 42, 185); sobre la importancia y desarrollo de esta vertiente dentro del complejo y lleno de porosidades pensamiento católico en Argentina, véase Zanca (2012). A su vez, en un plano cultural y social, recordemos que la Iglesia Católica en esta etapa no estuvo ajena -al igual que el SLyF- a los influjos del desarrollismo, entendido como clima cultural de época (Altamirano, 1998); al respecto véase Lida (2012:18).

34 Ídem.

35 Cabe aclarar que no abordamos aquí la enorme cantidad de actividades de índole cultural y deportiva que el SLyF organizaba asiduamente, y que podrían analizarse como formas de sociabilidad más amplias en las que éste ponía en juego las concepciones filosóficas que buscaba difundir entre la "familia lucifuercista".

36 Fueron mucho más numerosos en SEGBA que en el resto. Por dar un ejemplo, en 1967 allí se realizaron 1098 mientras que sólo 141 en la CIAE (SLyF CF, 1966-1967).

37 Véase convenio en Dinamis Interno, Año VIII N²42, julio 1975, p. 2.

38 Véase convenio en Dinamis Interno, Año VII N²29, 27/12/73, p. 18.

39 La Resolución $N^{\circ} 1756 / 72$ fue firmada en julio por el entonces Ministro de Cultura y Educación Eduardo Malek. Ya al año siguiente, el crecimiento de la Escuela obligó a buscar otro edificio que albergara a sus 360 alumnos/as. Dinamis Interno, Año VII N'221, 11/04/73, p. 29.

40 Estos funcionaron en la provincia de Buenos Aires. Acorde con los lineamientos de DINEA en esta época, los CENS constituían espacios: con fines culturales, político-sociales y de capacitación laboral; que adoptaron la estructura por "áreas de aprendizaje"; donde se incorporaba una metodología activa, participativa y dialogal. Para un análisis de la propuesta pedagógica de la "renovada DINEA” y el caso del SLyF en particular consultar Baraldo (2016, 2020). Es necesario aclarar que la articulación con DINEA tiene su antecedente bajo el gobierno militar, cuando en 1970 se abrieron ocho centros dependientes de dicho organismo donde se dictaban cursos de educación de adultos, los que funcionaban en diversos sectores de trabajo y Subsecretarías de zona de provincia y Capital. Dinamis Quincenal, Año IV N¹86, 20/05/1970, p.10.

41 Véase convenio en Dinamis Interno, Año VII N²29, 27/12/73, pp. 17-19.

42 Con el Ministerio de Educación de la Provincia de Buenos Aires y en sintonía con el Plan de Movilización Educativa se estableció la "mutua colaboración en todos los ámbitos de la educación"; con la Dirección de Cultura de la UBA se buscó realizar intercambios culturales y artísticos y con la Escuela de Servicio Social se firmó "un acuerdo de trabajo e investigación de carácter laboral”; mientras que con la Secretaría de Estado del Menor y la Familia se pretendió concretar "una integración cultural, artística y recreativa en favor de una rehabilitación de los menores y por la felicidad de los ancianos"; entre otros (SLyF CF, 1974e, p. 9). Estos convenios muestran que el SLyF no ponía límites ni etarios ni de formato a su búsqueda de una promoción cultural amplia e integral.

43 Estuvieron presentes los máximos representantes del Ministerio de Cultura y Educación de la Nación, CONET y DINEA (Jorge Taiana, Carlos Benítez y Carlos Grosso respectivamente).

44 Dinamis Interno, Año VII N²29, 27/12/73, p. 17 -resaltado en original.

45 Los otros eran: Cultural, Deportivo, Juventud y Femenino.

46 El proceso formativo se vio truncado por la dictadura, obturando la posibilidad de evaluar sus resultados en un mediano/ largo plazo. El gremio sufrió la escalada represiva a partir de este momento -con cesantías, persecuciones, asesinatos y desapariciones-, especialmente a partir del conflicto desatado entre mediados de 1976 y principios del año siguiente. Siendo que Luz y Fuerza contaba con uno de los convenios -el de 1975- más ventajosos, estuvo entre quienes más sufrieron las políticas económico-laborales del régimen militar; al respecto véase Ghigliani (2012).

47 Dinamis Quincenal, Año IV Nº186, 20/05/1970, p. 32.

48 En su estudio contemporáneo sobre educación sindical en Argentina, H. Belloni Ravest destaca que las actividades del ICS se realizaban "con el apoyo pedagógico de proyecciones cinematográficas, apuntes didácticos, mesas redondas, conferencias, y una excelente biblioteca especializada” (Belloni Ravest, 1973, p. 15). 
49 Revista Dinamis, Año XXI N89, marzo 1965.

50 El Curso especial para dirigentes gremiales de 1971 por ejemplo, estuvo orientado al análisis de la situación contemporánea a escala internacional y nacional (organizado por problemas: políticos, sociales, económicos, de la industria). Véase SLyF CF (1971, pp.18-21). En 1974, a lo largo de cuatro días se abordaron los siguientes ejes y temáticas: 1) Política: Estructura del poder político; Participación popular; Situación mundial y latinoamericana. 2) Economía: pautas y desarrollo para una política económica de liberación nacional. 3) Energía eléctrica: Cogestión. Autogestión. 4) Conducción sindical: La gran empresa nacional. Empresas regionales; Los trabajadores sindicalizados y el gobierno popular (SLyF CF, 1974c).

51 Duraban aproximadamente tres meses, con un cursado de 4-5 horas semanales en dos días. En 1967 y1968, por ejemplo, las materias ofrecidas fueron: Literatura, Relaciones humanas, Oratoria, Modelos de crecimiento económico, El sindicato ante los cambios estructurales, Doctrinas sociales comparadas (SLyF CF, 1966-1967, p. 14).

52 Por ejemplo, el de Interpretaciones del Convenio Colectivo de Trabajo, que dictaba el entonces secretario gremial Oscar Smith junto a integrantes de las distintas subcomisiones de convenio. Dinamis Quincenal, Año III Nº147, 07/08/1968.

53 La relación del SLyF con el sindicalismo norteamericano provocó fuertes denuncias en la época, especialmente de los sectores combativos nucleados alrededor de la CGT de los Argentinos, quienes los acusaban de ser instrumento de la "penetración yanqui" en el sindicalismo local. CGTA, Semanario CGT, Buenos Aires, 24/04/1969, p. 1.

54 La Facultad de Derecho y Ciencias Sociales de la UBA, la Universidad del Salvador, el Instituto Torcuato Di Tella, la Facultad de Ciencias Económicas de la Universidad de la Provincia de Buenos Aires, el Instituto del Trabajador Social, entre otras. La mayoría de los becados fueron varones, a excepción de quienes tuvieron a la última institución mencionada como destino.

55 Estos versaban sobre: Sociología, Relaciones humanas, Oratoria, Desarrollo comunitario, Economía, Negociación colectiva, Productividad, Cooperativismo, entre otras temáticas. AIFLD [IADSL], The AIFLD Report, Vol. $7 \mathrm{~N}^{\circ}$, Washington, septiembre 1969, pp. 5-6.

56 Dinamis Quincenal, Año IV N¹82, 04/03/1970, p. 1.

57 Revista Dinamis, Año XXI N¹04, 11/11/1965, p. 50.

58 Véase ORIT, Noticiario Obrero Interamericano, México D.F., septiembre 1970, p. 3.

59 Sin mencionarse la autoría de los mismos, algunos de ellos fueron: La nueva educación argentina; La educación sindical; La cultura nacional; El deporte nacional; Participación; La educación argentina $2^{a}$ parte: propuestas; Historia del Sindicato de Luz y Fuerza Capital; Historia del movimiento obrero argentino; Estudio de las actividades culturales, sociales y deportivas comparadas con otros sindicatos del mundo; La energía en la Argentina; Actividades sociales de los sindicatos en la Argentina; Los sindicatos en América Latina; La OIT y las centrales internacionales (SLyF CF, 1974c).

60 Dinamis Interno, Año VI N²11, 17/05/1972, p. 27.

61 Más adelante veremos plasmado en números este objetivo.

62 Dinamis Quincenal, Año IV N¹86, 20/05/1970.

63 Dinamis Interno, Año VII N²27, 31/10/73, p. 34.

$64 \mathrm{Si}$ bien no conocemos en detalle la actividad de los primeros tres años, es importante señalar que estos coinciden con la creación del Instituto de Capacitación y Formación Social Sindical (ICFSS) de la CGT normalizada en 1963, en el cual SLyF estuvo directamente involucrado. En sintonía con el ICS, el eje de intervención del ICFSS fue la preparación técnica y política de sus cuadros sindicales. Se buscaba "obtener en poco tiempo un plantel extraordinario de compañeros capaces de asumir puestos de dirección y gobierno en cualquier momento". CGT, Boletín Informativo Semanal, Buenos Aires, No 26, 9 al 15 de agosto de 1963, p. 10. El responsable de la Secretaría de Prensa, Cultura, Propaganda y Actas de la CGT a cargo de dicho Instituto fue el dirigente lucifuercista Luis Angeleri, y varios de los profesores provenían del ICS. Al respecto véase Scodeller (2013a).

65 No disponemos de mayor información respecto de la metodología de trabajo implementada.

66 Este listado constituye una síntesis con base en los programas de los años 1965, 1966 y 1967. Si bien los nombres de algunas materias se modifican mínimamente, lo sustancial, como el plantel docente que las dictó, se mantiene durante estos tres años.

67 Participaron previamente del Instituto de Formación Social Sindical creado en 1956 y vinculado a Acción Sindical Argentina. Contemporáneamente, lo hicieron en el ICFSS-CGT, a su vez articulados desde el Instituto de Educación y Capacitación de los Trabajadores del Centro Argentino de Economía Humana; véase Scodeller (2013b).

68 Taccone fue secretario gremial en su gremio (1957-60) y luego en la Federación (1961-63), secretario general en Capital entre 1964 y 1970, y presidente de SEGBA (1973-76). Angeleri ocupó la mencionada Secretaría de Prensa dentro de la CGT (1963-65) y la misma función en la FATLyF (1960-62), fue subsecretario general de Luz y Fuerza (1967-68) y director obrero en CIAE (1969-71). Smith fue secretario gremial del Sindicato a partir de 1964 y desde fines de la década ocupó el mismo cargo en la Federación, para regresar en 1974 al Sindicato de Capital como secretario general; fue secuestrado y desaparecido en 1977. Délfico estuvo a cargo de la Subsecretaría General Técnica del Sindicato desde 
1965 y a partir de 1969 de la Secretaría de Prensa, además fue director de la Revista Dinamis y posteriormente jefe de prensa de SEGBA.

69 Como para la etapa anterior, aquí hemos realizado una síntesis de los programas implementados entre 1968 y 1971 atendiendo a sus núcleos comunes, aunque a veces los nombres de cursos y clases presenten ciertas modificaciones o diferencias. Véase por ejemplo Dinamis Quincenal, Año III N¹47, 07/08/1968 o Año V N¹99, 31/03/1971, p. 12.

70 Reproducimos el programa correspondiente al Ciclo XIII de 1973. Con algunos cambios de nombres o fusiones/ divisiones, los programas son muy similares aunque no idénticos. En 1974 se reorganizaron las materias en cinco áreas: política, economía, sindicalismo, sociocultural; recursos naturales y energía. Las fuentes proveen escasa información sobre el plantel docente de estos años.

71 Por ejemplo, la materia Historia Política, Social y Económica Argentina de 1973 fue reemplazada al año siguiente por Historia Política Argentina y Latinoamericana, donde, si bien se repiten todos los contenidos de la primera, agregan un $5^{\circ}$ punto sobre "Latinoamérica, lengua, religión, cultura. Intereses que la desintegraron y los que persisten en ese intento". O la introducción del tema "el intento del ATLAS" en la materia Historia del movimiento obrero argentino e internacional.

72 Se realizó en septiembre de 1973. Los temas tratados fueron: "La Concepción Ideológica Justicialista: Relación entre ideología, doctrina y programa. La Organización Justicialista: Actualización programática. La Revolución Justicialista: Actualización programática. El Estado Justicialista: Relación entre política y tecnología. Las Empresas del Estado: Actualización tecnológica. La Conducción Empresaria: Actualización administrativa”. Dinamis Interno, Año VII N 226, 25/09/73, p. 29.

73 En este caso se coorganizó con la Secretaría Política de la Presidencia de la Nación y además de su responsable (J. Licastro) participaron en el dictado otros miembros del CTP como Carlos Groso y el entonces diputado nacional José Luis Fernández Valoni. Dinamis Interno, Año VII N²34, 23/08/74.

74 Véase respectivamente las Memorias y Balances 1965-1966, 1966-1967, 1967-1968 y Dinamis Quincenal, Año III N ${ }^{\circ} 150,18 / 09 / 1968$.

75 Dinamis Interno, Año VII N²23, 26/06/73, p. 24.

76 Dinamis Interno, Año VII N²27, 31/10/73, p. 34.

77 Dinamis Interno, Año VII N²35, 27/09/74, p. 34.

78 Dinamis Quincenal, Año IV Nº179, 17/12/1969 y Año V N¹95, 09/12/1970, p. 24, respectivamente.

79 Dinamis Interno, Año VIII N²36, 31/10/74, p. 26.

80 Dinamis Interno, Año VIII N $236,31 / 10 / 74$, p. 26.

81 Dinamis Interno, Año VIII N²37, 29/11/74, p.18.

82 Argumentaban: "aún nos seguimos debatiendo sobre si la universidad debe salir al pueblo... o si es el pueblo el que debe entrar... La solución no parece estar en difundir la universidad hacia afuera, ni infundir el pueblo en ella, sino fundir la universidad en el pueblo mismo, confundirla con la vida diaria del pueblo" (SLyF CF, 1974d, p. 37).

83 Se prolongaba durante un cuatrimestre con cuatro horas de asistencia semanal.

84 Desarrollado a lo largo de tres meses con un cursado de seis horas semanales.

85 En este último caso planteaban implementar con una modalidad intensiva (a lo largo de una semana con cursado mañana y tarde) una actividad ya desarrollada en el SLyF a fines de 1973.

86 Revista Dinamis, Año VI N63, diciembre de 1973, p. 50.

87 Este discurso, pronunciado en la CGT en octubre de 1973, fue altamente reproducido en las publicaciones del ICS. Puede leerse completo en Dinamis Interno, Año VII N²27, 31/10/73, pp. 4-5.

88 Su colaboración se menciona en los dos cuadernillos que dentro de la serie Apuntes para trabajar se editaron en 1974 sobre temas educativos: La nueva educación argentina y Educación sindical.

89 Revista Dinamis, Año II N¹3, octubre 1969, p. 155 -resaltado en original. 